14.10

\title{
Биологические и реологические свойства коллагена, сшитого глутаровым альдегидом
}

\author{
() Ю.А. Нащекина, ${ }^{1,2}$ О.А. Луконина, ${ }^{1}$ Д.М. Дарвиш, ${ }^{1}$ А.В. Нащекин, ${ }^{2}$ В.Ю. Елоховский, ${ }^{3}$ В.Е. Юдин, ${ }^{3}$ \\ Н.А. Михайлова ${ }^{1}$ \\ ${ }^{1}$ Институт цитологии РАН, \\ 194064 Санкт-Петербург, Россия \\ 2 Физико-технический институт им. А.Ф. Иоффре РАН, \\ 194021 Санкт-Петербург, Россия \\ ${ }^{3}$ Санкт-Петербургский политехнический университет Петра Великого, \\ 195251 Санкт-Петербург, Россия \\ e-mail: nashchekina.yu@mail.ru
}

Поступило в Редакцию 29 января 2020 г.

В окончательной редакции 29 января 2020г.

Принято к публикации 17 февраля 2020 г.

Изучено влияние концентрации глутарового альдегида, обладающего способностью сшивать молекулы коллагена I типа, на его стабильность, механическую прочность и цитотоксичность. Показано, что в физиологических условиях наибольшей стабильностью обладает коллаген, содержащий 10 и $18 \%$ глутарового альдегида. Результаты реологического анализа продемонстрировали, что при минимальной концентрации глутарового альдегида $(1 \%)$ механические характеристики коллагеновых гидрогелей существенно улучшаются. Однако концентрация глутарового альдегида выше 10\% снижает жизнеспособность клеток на 50\%.

Ключевые слова: коллаген I типа, глутаровый альдегид, химическая сшивка, деградация.

DOI: $10.21883 /$ JTF.2020.09.49697.33-20

\section{Введение}

Коллаген является самым распространенным белком в тканях человека. К настоящему времени известно 28 типов коллагенов [1], различия между которыми обусловлены структурной сборкой основной полипептидной цепи, их локализацией в тканях, выполняемыми функциями и т.д. Самым распространенным белком в организме является коллаген I типа, который образует более $90 \%$ органической массы кости и является основным компонентом сухожилий, кожи, связок, роговицы и многих межсуставных соединительных тканей, за исключением гиалинового хряща, мозга и стекловидного тела глаза. Основная функция коллагена в организме поддержание структурной целостности тканей и органов.

Для эффективного лечения патологий и восстановления поврежденных тканей и органов используют современные технологии, среди которых важное место занимают клеточные, основанные на трансплантации клеток человека на разнообразных носителях (скаффолдах) [2]. Формирование таких носителей на базе основного структурного элемента соединительной ткани, а именно коллагена I типа, представляется перспективным. В процессе биосинтеза коллагена in vivo между молекулами образуются поперечные связи, придающие фибриллам коллагена стабильную структуру, механическую прочность и устойчивость к действию ферментов. Однако в процессе выделения коллагена из нативных тканей эти связи разрушаются, и он теряет свою прочность. Разработка механически прочного геля методом сшивания коллагена, предназначенного для создания скаффолдов, культивирования и трансплантации клеток, является одной из актуальных задач современной регенеративной медицины.

В настоящее время для сшивания коллагена используют физические и химические агенты. Одним из химических агентов, формирующих прочные межмолекулярные сшивки, является глутаровый альдегид (ГА), являющийся линейным 5-углеродным диальдегидом. ГА широко применяется в качестве сшивающего агента для биомедицинских материалов на основе коллагена $[3,4]$. Механизм сшивания молекул коллагена с помощью ГА (рис. 1) заключается в реакции первичных остатков аминогрупп (гидроксил)-лизина в молекуле коллагена

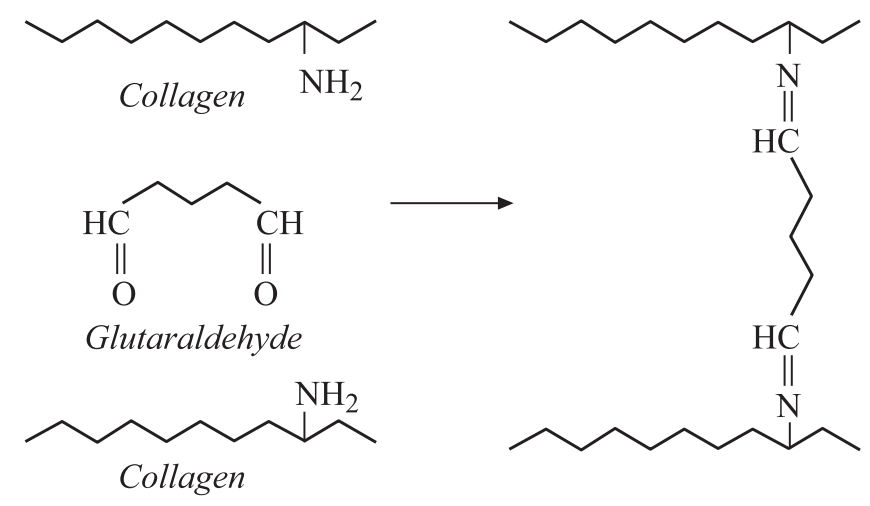

Рис. 1. Механизм реакции сшивания молекул коллагена с помощью ГА [6]. 
с образованием промежуточных оснований Шиффа, которые затем превращаются в стабильные и сложные поперечные связи. Обычно 6-8 молекул ГА участвуют в одной сшивке „лизин-лизин“ [5].

Несмотря на широкое использование ГА в медицинских продуктах, публикуются данные о его цитотоксичности [3,6-8] и способности инициировать неспецифическую кальцификацию тканей $[7,8]$.

\section{1. Экспериментальная часть}

\section{1. Материалы}

\subsection{1. Выделение коллагена I типа}

Коллаген I типа был выделен по модифицированный методике [11] из сухожилий крысиных хвостов, предварительно промытых физиологическим раствором $(0.9 \%$ раствор $\mathrm{NaCl})$. Коллаген I типа экстрагировали $0.5 \mathrm{M}$ уксусной кислотой, после растворения его осаждали сухой солью $\mathrm{NaCl}(0.9 \mathrm{M}$ раствор). Для отделения коллагена от соли раствор диализовали сначала в растворе уксусной кислоты, увеличивая последовательно концентрацию кислоты от 0.1 до $0.5 \mathrm{M}$. После растворения коллаген осаждали в фосфатном буфере. На последнем этапе проводили диализ против раствора уксусной кислоты (с добавлением хлороформа для стерилизации), постепенно уменьшая ее концентрацию до $1: 1000$.

\subsection{2. Химическая сшивка раствора коллагена I типа с помощью ГА}

Образцы коллагена с концентрациями 1,2 и $3 \mathrm{mg} / \mathrm{ml}$ были получены путем разбавления коллагена с концентрацией $5.9 \mathrm{mg} / \mathrm{ml} \quad 0.1 \mathrm{M}$ раствором уксусной кислоты (НеваРеактив, РФ).Сшивание осуществляли добавлением к раствору коллагена раствор сшивающего агента с конечной концентрации ГА 1, 5, 10 и 18mass.\% (концентрацию ГА рассчитывали по отношению к массе сухого белка). После взаимодействия с ГА раствор коллагена переходил в гелеобразное состояние. Полученный субстрат несколько раз промывали фосфатным буфером.

Для оценки механических свойств были сформированы гели с концентрацией коллагена $2 \mathrm{mg} / \mathrm{ml}$. Для этого в состав раствора коллагена I типа для подведения физиологической ионной силы была введена среда 199 (10 кратная) (Gibco, CША), а для подведения $\mathrm{pH}-$ раствор $\mathrm{NaOH}$ в соответствующих пропорциях. Разбавление раствора до конечной концентрации осуществляли добавлением фосфатного буфера. Полученные гели выдерживали в растворе ГА с концентрацией 1, 5, 10 и 18 \%. По истечении 1 суток гели промывали в фосфатном буфере и проводили механические испытания.

\section{2. Методы исследования}

\subsection{1. Оценка деградации коллагена}

Для оценки деградации коллагена в физиологических условиях использовали модифицированный метод Лоури [12]. Метод основан на реакции белков с солями меди (II) в щелочном растворе и восстановлении фосфорно-молибдено-вольфрамового реактива (реактив Фолина) с образованием окрашенных в голубой цвет продуктов.

Для изучения процесса деградации к сшитому коллагену добавляли раствор фосфатного буфера (PBS) и оставляли эту смесь в термостате при температуре $37^{\circ} \mathrm{C}$. Оценку деградации проводили по истечении 1.4 и 7 суток, анализируя содержание белка в растворе PBS методом Лоури. По оптической плотности растворов, измеренной при длине волны $650 \mathrm{~nm}$, определяли количество белка, вышедшего в раствор PBS. Процент деградации вычисляли по формуле

$$
\frac{A}{B} \cdot 100 \%=C,
$$

где $A$ - количество белка, вышедшего в раствор PBS, $[\mathrm{mg}] ; B$ - общее количество белка в растворе коллагена, $[\mathrm{mg}] ;$ - процент деградации, [\%].

\subsection{2. Реологические испытания}

Реологические испытания проводили в реометре MCR301 (Anton Paar, Австрия) в измерительном узле плоскость-плоскость РP20 (диаметр $25 \mathrm{~mm}$, зазор $1 \mathrm{~mm}$, DIN 53018-1) при температуре $25^{\circ} \mathrm{C}$ в динамическом (частотном) режиме со снижением частоты от 20 до $0.02 \mathrm{~Hz}$ ( 5 точек на логарифмическую декаду). Время тестирования на каждой точке определялось реометром.

\subsection{3. Культивирование мезенхимных стволо- вых клеток человека}

В настоящей работе использовали нетрансформированную клеточную линию FetMSC из Коллекции культур клеток позвоночных (Институт цитологии РАН). Культивирование клеточной линии осуществляли в асептических условиях при постоянных значениях температуры $37^{\circ} \mathrm{C}$, влажности $98 \%$, содержании $\mathrm{CO}_{2} 5 \%$.

Для культивирования FetMSC использовали DMEM/F12 (Росмедбио, РФ) с добавлением 10\% сыворотки эмбрионов коров (СЭК) (HyClone, США), 1\% антибиотика Penicillin-Streptomycin (Gibco, США) и 1\% глутамина (Lonza, Швейцария).

Для снятия клеток с поверхности культурального сосуда проводили их обработку протеолитическими ферментами - Трипсин $(0.25 \%)$ ЭДТА (Sigma-Aldrich, США). Ферменты дезактивировали путем добавления среды с сывороткой, перемешивания и центрифугирования при скорости вращения $1000 \mathrm{rpm}$ в течение 3 min. Затем супернатант сливали, к клеткам добавляли 
питательную среду DMEM F12 с добавлением 10\% бычьей сыворотки, $1 \%$ глютамина и $1 \%$ антибиотика, хорошо перемешивали и считали количество клеток в камере Горяева.

\subsection{4. Оптическая микроскопия}

В процессе культивирования клеток проводили наблюдение с фотофиксацией с помощью инвертированного микроскопа EclipseTS100 (Nikon, Япония), оснащенного фотокамерой.

\subsection{5. Оценка жизнеспособности FetMSC с по- мощью МТТ-теста}

Метод основан на способности живых клеток восстанавливать желтый бромид 3-(4,5-диметилтиазол-2-ил)2,5-дифенилтетразолия (МТT) (Sigma-Aldrich, США) с образованием пурпурно-синих кристаллов формазана, растворимых в ДМСО (Биолот, РФ). После 4 суток культивирования к клеткам добавляли стоковый раствор MTT с концентрацией $5 \mathrm{mg} / \mathrm{ml}$ в среде $\alpha$-MEM и выдерживали в $\mathrm{CO}_{2}$-инкубаторе при $37^{\circ} \mathrm{C}$ в течение $3 \mathrm{~h}$ до появления пурпурно-синих кристаллов формазана. Аккуратно отбирали среду, добавляли $50 \mu 1$ ДМСО. Оптическую плотность растворов измеряли на спектрофотометре АИФР-01/УНИПЛАН (Пикон, РФ) при длине волны $570 \mathrm{~nm}$.

\section{2. Результаты и их обсуждение}

\section{1. Оценка скорости деградации коллагена I типа разной концентрации}

Первоначально необходимо было оценить влияние различных концентраций коллагена $(1,2,3 \mathrm{mg} / \mathrm{ml})$ в присутствии $1 \%$ ГА на скорость деградации. В качестве контролей были выбраны растворы коллагена I типа соответствующих концентраций без сшивающего агента.

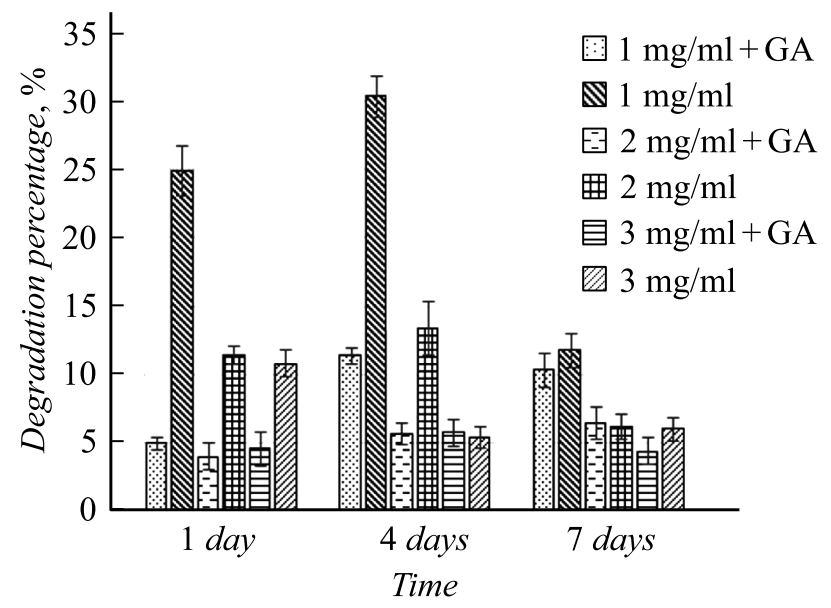

Рис. 2. Влияние концентрации коллагена и ГА на скорость деградации.

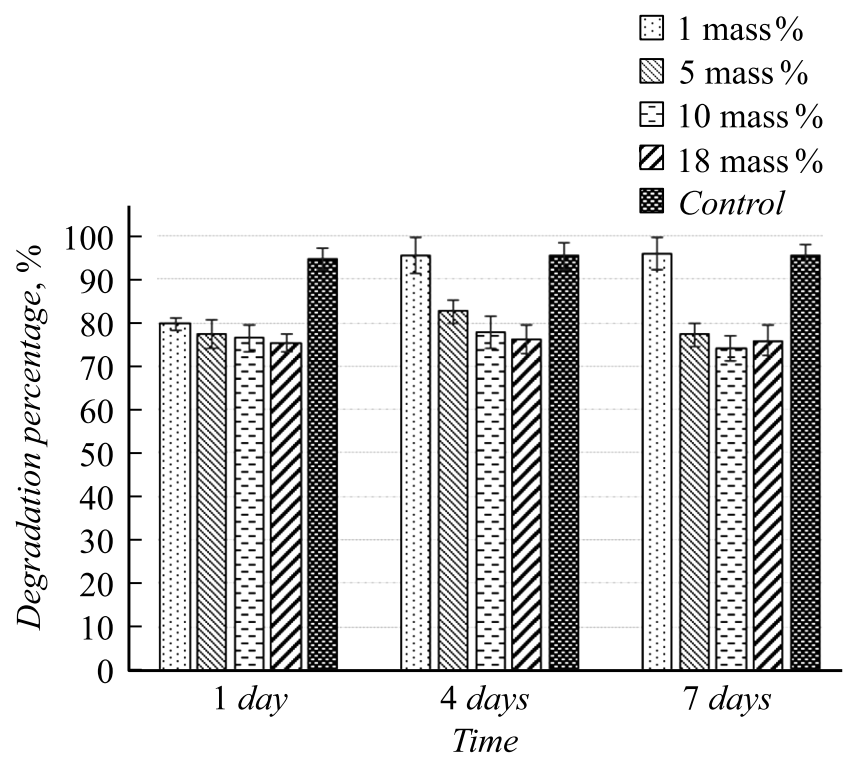

Рис. 3. Влияние концентрации ГА на скорость деградации раствора коллагена I типа.

Деградация раствора коллагена со сшивающим агентом происходит в $2-2.5$ раза медленнее по сравнению с контролем (рис. 2). Показано, что в течение первых суток эксперимента количество коллагена, вышедшего в раствор PBS в присутствии ГА, не зависит от концентрации коллагена. Однако на 4 и 7 сутки процент деградации становится ниже в 2 раза для раствора коллагена с концентрациями 2 и $3 \mathrm{mg} / \mathrm{ml}$. На 7 сутки наблюдали резкое снижение скорости деградации.

Скорость деградации коллагена без добавления сшивающего агента уменьшается с увеличением концентрации белка. Коллаген с концентрацией $3 \mathrm{mg} / \mathrm{ml}$ сшивается хуже по сравнению с коллагеновыми образцами с концентрацией 1 и $2 \mathrm{mg} / \mathrm{ml}$, о чем свидетельствует разница в процентах деградации, а коллаген с концентрацией $1 \mathrm{mg} / \mathrm{ml}$ при сшивании деградирует сильнее, в дальнейшем все исследования проводили на основе коллагена с концентрацией $2 \mathrm{mg} / \mathrm{ml}$.

\section{2. Оценка скорости деградации коллагена I типа с добавлением разного количества ГA}

На рис. 3 показано влияние различных массовых концентраций ГА на скорость деградации раствора коллагена с концентрацией $2 \mathrm{mg} / \mathrm{ml}$. Контрольный образец сравнения - аналогичный коллаген без добавления сшивающего агента.

Минимальная скорость деградации раствора коллагена достигается при добавлении сшивающего агента в количестве 10 и $18 \%$ (рис. 3). По сравнению с контролем в первые сутки наблюдали уменьшение деградации уже при добавлении ГА в количестве 1\%.Степень деградации для коллагена с концентрацией ГА 5,10 и $18 \%$ остается 
постоянной на протяжении всего времени деградации, тогда как коллаген с добавлением 1\% ГА со временем деградирует быстрее и приближается по значению к контрольному образцу.

\subsection{1. Реологический анализ}

На рис. 4 и 5 представлены зависимости модулей сдвига $\left(G^{\prime}\right)$ и потерь $\left(G^{\prime \prime}\right)$ при сдвиге исходного и сшитого коллагенового геля в зависимости от концентрации ГА. Для каждого образца гидрогеля коллагена $G^{\prime \prime}$ является почти постоянной величиной, в то время как $G^{\prime \prime}$ незначительно изменяется в пределах измеренных частот, что указывает на механическую стабильность исследуемых гидрогелей в диапазоне частот от 0.01 до $10 \mathrm{~Hz}$. Значения $G^{\prime}$ и $G^{\prime \prime}$ увеличиваются с увеличением концентрации ГА, что свидетельствует о том, что сшитые гидрогели коллагена более устойчивы к

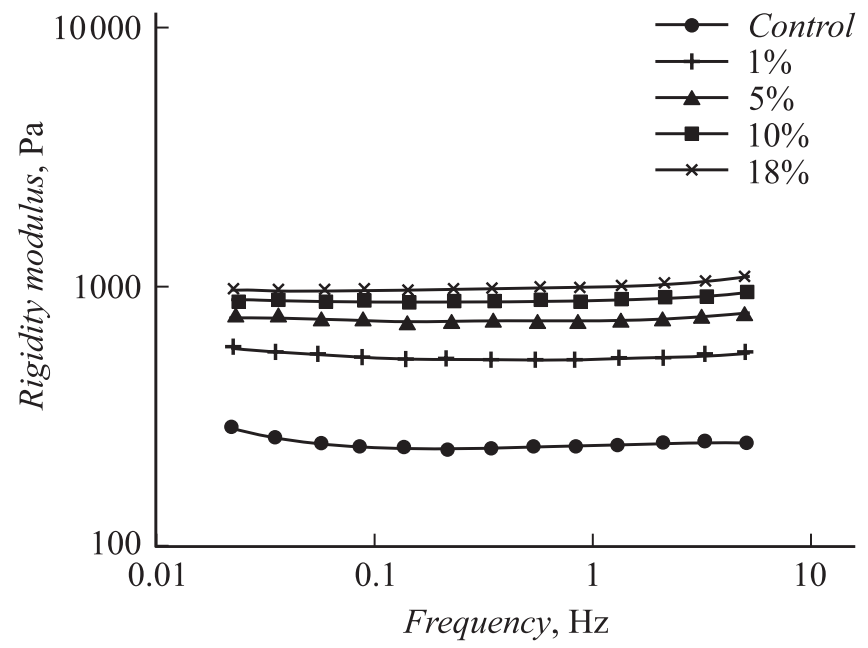

Рис. 4. Зависимость $G^{\prime}$ сшитого коллагенового геля от концентрации ГА.

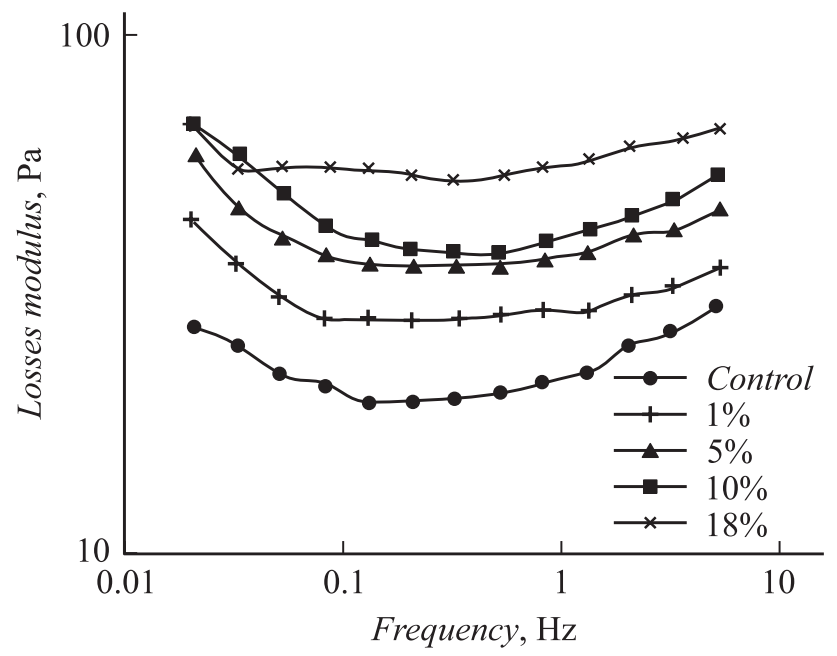

Рис. 5. Зависимость $G^{\prime}$ сшитого коллагенового геля от концентрации ГА.

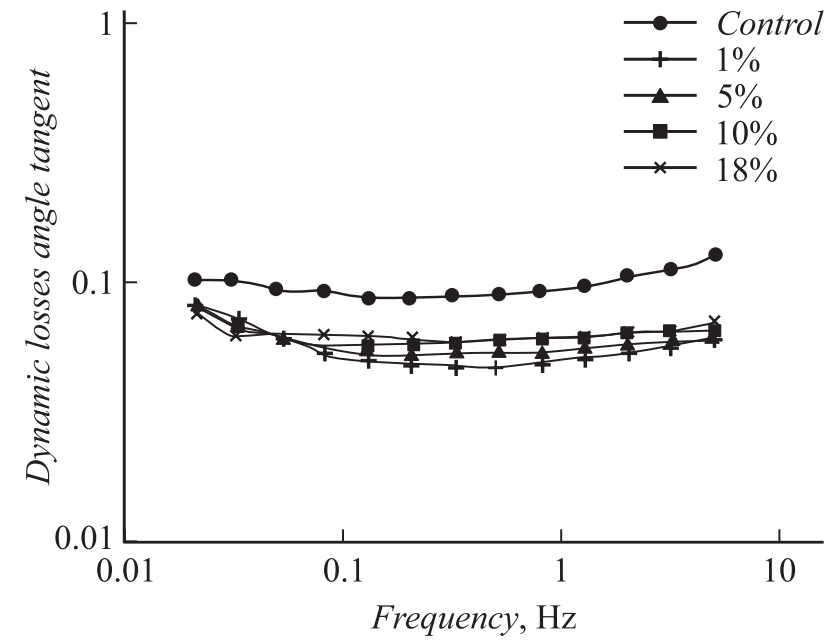

Рис. 6. Зависимость $\operatorname{tg} \delta$ сшитого коллагенового геля от концентрации ГА.

деформации текучести, чем нативный коллагеновй гидрогель. А именно чем выше степень сшивки, тем лучше устойчивость к внешним силам. Полученные результаты демонстрируют, что модули сдвига и потерь в несколько раз больше, чем у природного гидрогеля коллагена.

Тангенс угла динамических потерь $(\operatorname{tg} \delta)$ определяется как отношение $G^{\prime \prime}$ к $G^{\prime \prime}$, и поэтому значение $\operatorname{tg} \delta>1$ свидетельствует о то, что для исследуемого образца доминирующим в данном диапазоне температур и частот является вязкое поведение, подобное жидкости. При значениях $\operatorname{tg} \delta<1$ для материала образца характерно в большей степени упругое или „твердоподобное“ поведение [13]. На рис. 6 показаны кривые $\operatorname{tg} \delta$ нативного и сшитых гидрогелей на основе коллагена. Значения $\operatorname{tg} \delta \leqslant 0.14$ означают, что все гидрогели обладают значимой упругостью и, более того, значение $\operatorname{tg} \delta$ гидрогеля коллагена уменьшается от 0.14 до 0.07 с увеличением дозы ГА, подтверждая, что сшитые гидрогели коллагена демонстрируют в большей степени упругое поведение.

\section{3. Морфологический анализ FetMSC при инкубировании на коллагене, сшитом ГА}

В качестве контроля для всех образцов использовались FetMSC, культивируемые на лабораторном пластике.

Изучение морфологии клеточной линии FetMSC, культивируемых на коллагене (рис. 7) в присутствии ГА, с помощью световой микроскопии показало явное цитотоксическое влияние альдегида на клетки. Морфология и степень распластанности клеток отличались от клеток, культивируемых на пластике и на коллагене без ГА. В случае присутствия ГА в больших концентрациях клетки принимали округлую форму, при низкой концентрации ГА форма клеток и степень их распластанности не отличалась от контрольного образца. 


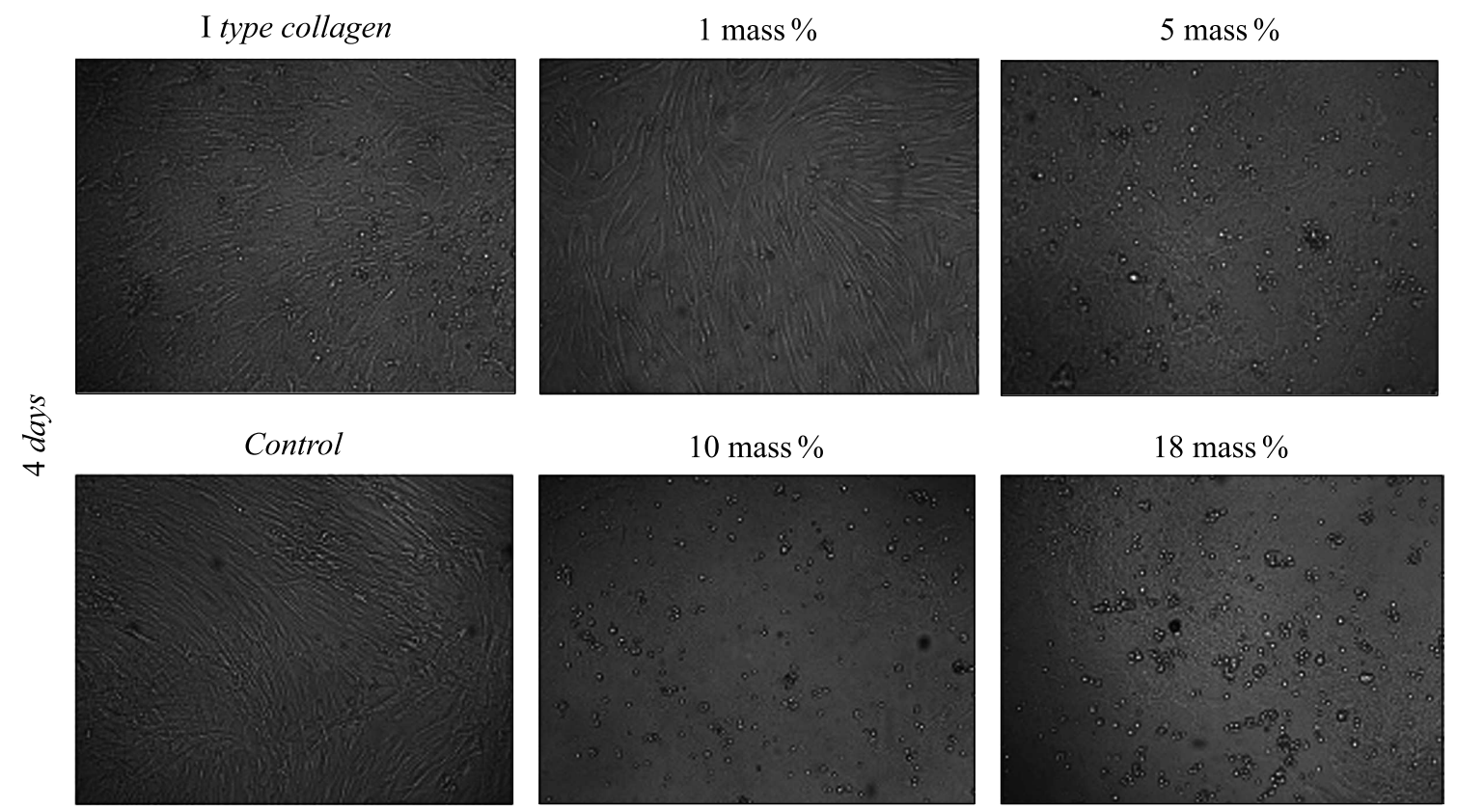

Рис. 7. Оптическая микроскопия FetMSC человека на растворе коллагена I типа в присутствии ГА (увеличение $10 \times$ ).

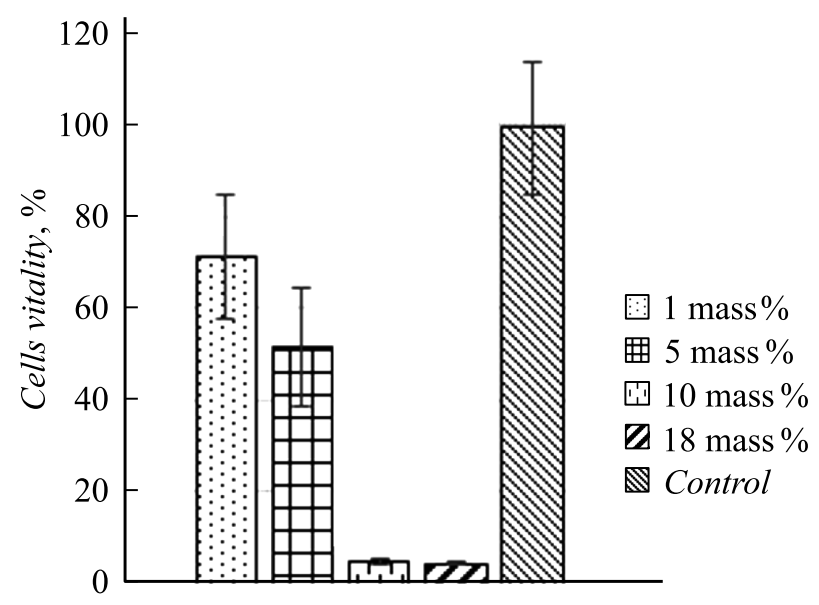

Рис. 8. Жизнеспособность FetMSC после инкубирования на коллагене в присутствии ГА после 4 суток культивирования.

\section{4. Определение жизнеспособности FetMSC при росте на коллагене, сшитом ГА}

В качестве контроля для оценки жизнеспособности FetMSC использовали раствор коллагена I типа с конечной концентрацией белка $2 \mathrm{mg} / \mathrm{ml}$. На рис. 8 представлена гистограмма, отражающая влияние различных концентраций ГА на жизнеспособность FetMSC. Данные MTT анализа подтверждают результаты оптической микроскопии. Жизнеспособность клеток в присутствии ГА ниже, чем в контроле, и увеличение концентрации ГА уменьшает жизнеспособность FetMSC.

Результаты свидетельствуют о цитотоксичности ГА, что согласуется с литературными данными [3,6-8].

\section{Заключение}

В результате проведенных исследований было показано, что присутствие ГА в растворе коллагена, выделенного методом кислотной экстракции, способствует уменьшению скорости деградации белка в физиологических условиях. Следует отметить, что чем выше концентрация ГА, тем меньше скорость его деградации и выше стабильность при динамических нагрузках. Однако увеличение концентрации ГА в коллагене существенно снижает жизнеспособность клеток. Оптимальной концентрацией ГА для стабилизации коллагена являются значения в пределах от 1 до 5\% ГА.

\section{Финансирование работы}

Работа по приготовлению коллагеновых образцов и биологические испытания выполнена при финансовой поддержке РФФИ (проект № 20-03-00400_а). Работа по механическим испытаниям выполнена при финансовой поддержке РНФ (проект 19-73-30003).

\section{Конфликт интересов}

Авторы заявляют, что у них нет конфликта интересов.

\section{Список литературы}

[1] Sandhu S.V., Gupta S., Bansal H., Singla K. // J. Orof. Res. 2012. Vol. 2. N 3. P. 153-159.

[2] Нащекина Ю.А., Юдинцева Н.М., Никонов П.О., Иванова Е.А., Смагина Л.В., Воронкина И.В. // Кл. техн. биол. мед. 2017. № 1. C 12-18. 
[3] Scheffel D.L.S., Soares D.G., Basso F.G., de Souza CostaC.A., Pashley D., Hebling J. // J. Dent. 2015. Vol. 43. N 8. P. $997-$ 1006. DOI: $10.1016 /$ j.jdent.2015.05.004

[4] Peng Y.Y., GlattauerV̈., Ramshaw J.A.M. // Int. J. Biom. 2017. N 1. P. 1-6.DOI: $10.1155 / 2017 / 8947823$

[5] Chandran P.L., Paik D.C., Holmes J.W. // Conn. Tiss. Res. 2012. Vol. 53. N 4. P. 285-297. DOI: $10.3109 / 03008207.2011 .640760$

[6] Lee C., Grodzinsky A., Spector M. // Biom. 2001. Vol. 22. N 23. P. 3145-3154.

[7] Umashankar P., Kumari T., Mohanan P. // Tox. Int. 2012. Vol. 19. N 1. P. 51-58. DOI: 10.4103/0971-6580.94513.

[8] Gough J.E., Scotchford C.A., Downes S. // J. Biom. Mat. Res. 2002. Vol. 61. N 1. P. 121-130. DOI: $10.1002 / \mathrm{jbm} .10145$

[9] Sheu M.T., Huang J.C., Yeh G.C., Ho H.O. // Biom. 2001. Vol. 22. N 13. P. $1713-1719$.

DOI: $10.1016 / \mathrm{s} 0142-9612(00) 00315-\mathrm{x}$

[10] Lai J.Y., Ma H.K. // Int. J. Nan. 2013. N 8. P. 4157-4168. DOI: $10.2147 /$ IJN.S52731

[11] Chandrakasan G., Torchia D.A., Piez K.AJ. // Biol. Chem. Vol. 1967. Vol. 251. P. 6062-6067.

[12] Дарбре А. Практическая химия белка. М.: Мир, 1989. $623 \mathrm{c}$.

[13] Tian Z., Liu W., Li G. // Pol. Degr. Stab. 2016. Vol. 130. P. 264-270.

http:// dx.doi.org/10.1016/j.polymdegradstab.2016.06.015 